\title{
Tüketicilerin İthal Tarım Ürünleri Konusundaki Tutum ve Davranışlarının Belirlenmesi: Samsun İli Örneği, Türkiye
}

\author{
Osman KILIÇ ${ }^{*}$, Gamze AYDIN ERYILMAZ ${ }^{2}$ \\ ${ }^{l}$ Ondokuz Mayls Üniversitesi, Ziraat Fakültesi, Tarım Ekonomisi Bölümü, Samsun, TÜRKIYE \\ ${ }^{2}$ Ondokuz Mayıs Üniversitesi, Samsun Meslek Yüksekokulu, Park ve Bahçe Bitkileri Bölümü, Samsun, TÜRKIYYE
}

\begin{tabular}{ll}
\hline \multicolumn{1}{c}{ Geliş Tarihi/Received: 21.07 .2020} & Kabul Tarihi/Accepted: 19.10 .2020 \\
\hline ORCID ID (Yazar sirasina göre / by author order) \\
\hline (D) orcid.org/0000-0002-0129-4034 (D) orcid.org/0000-0002-4440-8687 \\
"Sorumlu Yazar/Corresponding Author: okilic@omu.edu.tr
\end{tabular}

Öz: Araştırmanın amacı, Samsun ili kentsel alanda ikamet eden tüketicilerin ithal tarım ürünleri konusundaki tutum ve davranışlarını belirlemektir. Veriler, ailede gıda satın alma kararında etkili olan 384 tüketiciden anket yoluyla elde edilmiştir. Araştırma sonuçlarına göre, anket yapılan tüketicilerin \% 55.99'u son bir yılda en az bir kez ithal tarım ürünü tüketmiștir. En fazla tüketilen ithal tarım ürünleri \% 57.37 ile baklagiller, \% 37.82 ile meyveler ve \% 19.87 ile et ve mamulleridir. Yerli tarım ürünü tercih eden tüketiciler başlıca gerekçe olarak, yerli üretimi ve yerli gıda sanayini korumayı gösterirken, ithal tarım ürünü tüketenlerin başlıca gerekçesi yüksek teknolojiyle üretilen ürünler olduğunu düşünmeleridir. Tüketicilerin \% 83.59'u gelişmiş, \% 14.85'i gelişmekte ve sadece \% 1.56'sı az gelişmiş ülke kaynaklı ithal tarım ürünlerine daha fazla güvendiklerini belirtmişlerdir. Tüketicilerin Müslüman ülkelerden ithal edilen tarım ürünlerine karşı güven duygusu \% 76.3 iken, bu oran Müslüman olmayan ülkelerden ithal edilen ürünler için \% 23.7'dir. Araştırma sonuçları, tüketicilerin yerli ve ithal tarım ürünleri tercih etmelerindeki nedenlerin birbirinden farklı olduğunu göstermektedir. Tüketiciler yerli tarım ürünü tercihlerinde daha çok milli duygularla hareket ederken, ithal tarım ürününde üretim tekniği ve fiyat öne çıkmaktadır. İthal tarım ürünleri konusunda tüketici beklentilerini dikkate alan stratejilerin geliştirilmesi, yoğun rekabet ortamında firmaların kârlarını artırmalarına ve sektörde uzun süre varlıklarını devam ettirmelerine katkı sağlayacaktır.

Anahtar Kelimeler: İthal tarım ürünü, yerli tarım ürünü, tarım ürünleri tüketimi, tüketici tutum ve davranış1

\section{Determination of Consumers' Attitudes and Behaviors on Imported Agricultural Products: A Case Study in Samsun Province, Turkey}

\begin{abstract}
The aim of the research is to determine the attitudes and behaviors of consumers on imported agricultural products in the urban area of Samsun city. The data were obtained through a questionnaire from 384 consumers who were effective in the decision to purchase food in the family. According to the research results, $55.99 \%$ of consumers surveyed consumed imported agricultural products at least once in the last year. The most consumed imported agricultural products were legumes $(57.37 \%)$, fruits $(37.82 \%)$, and meat and meat products $(19.87 \%)$. While consumers who preferred domestic agricultural products showed the protection of domestic production and the domestic food industry as the main reasons, those who consumed imported agricultural products were considered the main reason as to be products produced with high technology. Of all consumers, $83.59 \%$ stated that they were more confident with imported agricultural products originating from developed countries, $14.85 \%$ from developing countries, and only $1.56 \%$ from less developed countries. While the consumers' trust in agricultural products imported from Muslim countries was $76.3 \%$, this rate was $23.7 \%$ for products imported from non-Muslim countries. The research results showed that the reasons why consumers preferred domestic and imported agricultural products differed from each other. While consumers acted mostly with national feelings in their domestic agricultural product preferences, production technique and price came to the fore in imported agricultural products. Developing strategies that take into account consumer expectations regarding imported agricultural products will contribute to the increase in profits of companies within an intensive competition and their long-term survival in the sector.
\end{abstract}

Keywords: Imported agricultural product, domestic agricultural product, agricultural product consumption, consumer attitude and behavior 


\section{Giriş}

Dünyada küreselleşme süreciyle birlikte, pek çok ürün dış ticaret yoluyla ülke pazarlarına sunulmaya başlanmıştır. Bu yeni dönemde ülkeler arasındaki ticari ilişkilerin artmasıyla, pazarlama olgusu ve satış kavramı farklı boyutlara taşınmıştır. Çok uluslu firmaların hâkim olduğu bu pazar anlayışında, ürünler eskiye oranla çok daha hızlı bir şekilde tüketicilere sunulabilmektedir. Tüketicilerin dünyanın herhangi bir ülkesinde üretilen ürünlere kolayca ulaşabilmeleri, yurt içi pazarda yerli ve ithal ürünler arasındaki rekabeti artırmıştır. Türkiye, küreselleşmenin arttığı bu süreçte sahip olduğu tarım potansiyeli ve gelişen gıda sanayisiyle birlikte, uluslararası pazarda kendine önemli bir yer edinmiştir. Hızla büyüyen nüfus ve küreselleşme sürecinde değişen tüketim alışkanlıkları doğrultusunda, küçük ve orta ölçekli firmaların hâkim olduğu Türk gıda sanayi, üretim teknolojilerinin yenilenmesiyle günden güne büyük ve çok uluslu işletmelerin yer aldığı bir endüstri yapısına kavuşmuştur (Öndoğan, 2002). Türkiye'de uluslararası ticari ilişkilerin ivme kazanmasıyla, ithal tarım ürünleri giderek iç pazarda daha fazla yer bulmuştur. Dünya tek ve büyük bir pazara dönüşürken, bu dönüşüm Türkiye'deki tüketici eğilimlerini ve beklentilerini de değiştirmiştir. Pazarlamanın temeli, tüketici memnuniyeti ve tatmini üzerine inşa edilmektedir (Şahin ve Sanc1, 2017).

Tüketici tutumu, bir ürüne karşı hissedilen olumlu ya da olumsuz duyguları ifade etmektedir. Tüketici davranışı ise mal ve hizmetlerin neden, nasıl ve ne zaman satın alındıklarını göstermektedir. Bu yönüyle tüketici davranışı, kavramsal olarak insan davranışlarının önemli bir parçasını teşkil etmektedir (Özden, 2017). Ancak tüketiciler satın alma kararlarında her zaman rasyonel davranmadıkları için, bir ürünün özelliklerinin iyi olması ve tüketicilere maksimum fayda sağlaması o ürünün satın alınması için yeterli değildir (Yücel ve Şimşek, 2018). Bu durum, değişen ve küreselleşen sosyo-kültürel ve ekonomik yapının, tüketici tercihlerine etkisi ve bu etkinin kişilere göre farklılık göstermesiyle açıklanabilir (Eryılmaz ve ark., 2018). Küresel rekabet ortamında yaşanan büyük değişimlere paralel olarak, her alanda olduğu gibi pazarlama alanında da bazı önemli aşamalardan geçilmiş ve bugünkü düzeye ulaşılmıştır. Başarılı işletmeler, geleneksel pazarlama anlayışından modern pazarlamaya geçişlerini tamamlamış, müşteri odaklı pazarlamanın devamı olan ve uzun dönemli müşteri ilişkisini esas alan ilişkisel pazarlama uygulamalarını strateji olarak benimsemişlerdir (Tekin ve ark., 2014). Tüketici davranışında kişisel özelliklerle birlikte dış faktörlerin de önemli etkisi vardır. $\mathrm{Bu}$ davranışın, dış faktörlere bağlı olarak değişeceği ve zamanla söz konusu faktörlerle uyumlu bir yapıya dönüşeceği kabul edilmektedir. Bir tüketicinin diğerinin davranışını etkileyebilme ve şekillendirebilme gücü, pazarlamanın sürekli geliştirilmesi gereken bir alan olduğunu göstermektedir. Yalçın (2003)'a göre ithal bir ürün; pazar potansiyelinin belirlenmesi, pazarın değerlendirilmesi, tüketici araştırmaları, hedef kitlenin ortaya konulması, satış tahminleri, tanıtım programlarının hazırlanması, ambalaj ve etiket özelliklerinin belirlenmesi, dağıtım maliyetinin hesaplanması, satış çabalarının organize edilmesi ve fiyatlandırma gibi temel çalışmalar yapıldıktan sonra yerli ürünlerle rekabet edebilecek konuma gelmektedir.

Bir ürünün pazarlanması ve tüketilmesindeki en dinamik aktörün tüketici olduğu gerçeğinin yanı sıra, tarım ürünleri dış ticaretinde yaşanan hızlı gelişmeler, ithal tarım ürünleri konusunda tüketici tutum ve davranışlarını inceleyen akademik çalışmaların önemini artırmıştır. Piyasadaki tüketici odaklı değişimi belirlemek amacıyla, yerli ve ithal tarım ürünleri konusunda birbirinden farklı ve sürekli değişen tüketici beklentilerini ortaya koyan araştırmalar, sektördeki firmalara artan rekabetten dolayı önemli avantajlar sağlayacaktır. $\mathrm{Bu}$ araştırmanın amac1, Samsun ili kentsel alanda yaşayan tüketicilerin sosyo-ekonomik özellikleri çerçevesinde, ithal tarım ürünleri konusundaki tutum ve davranışlarının belirlenmesidir. Araştırmadan elde edilen sonuçlar, tüketici istek ve beklentileriyle ilgili yerli ve ithal tarım ürünleri piyasasındaki aktörlere önemli bilgiler vereceği gibi, ileride yapılacak benzer araştırmalarla da karşılaştırma imkânı sağlayacaktır.

\section{Materyal ve Yöntem}

Araştırma alanı olarak, Samsun ili merkezinde yer alan ve en fazla kentli nüfusa sahip Atakum, Canik ve İlkadım ilçeleri seçilmiştir. Veriler, bu ilçelerde ikamet eden ve tarım ürünlerinin satın alınmasında etkili olan tüketicilerden, 2019 yılında yapılan anketlerden elde edilmiştir. Anket yapılan tüketici sayısının belirlenmesinde, Eşitlik 1'de verilen Cochran örnekleme formülü kullanılmıştır (Barlett ve ark., 2001).

$$
n=\frac{(t)^{2}(p)(q)}{(d)^{2}}, n=\frac{(1.96)^{2}(0.5)(0.5)}{(0.05)^{2}}=384
$$

Eşitlikte; $n$ örnek hacmini, $t$ \% 95 güven derecesine karşılık gelen tablo değerini, $p$ incelenen olayın meydana gelme olasılığını (0.5), $q$ incelenen olayın meydana gelmeme olasılığını $(q=1-p), d$ izin verilen hata payını (\% 5) ifade 
etmektedir. Buna göre, anket yapılan tüketici sayısı 384 olarak belirlenmiştir.

Araştırmada anket formu; tüketici ve ailesine ait sosyo-ekonomik özellikler, ithal tarım ürünlerinin tüketilme durumu, tüketilen ürün çeşitleri, yerli ve ithal tarım ürünlerinin tercih edilme nedenleri ile tüketicilerin ithalatçı ülkelere karşı güvenilirlik algılarına yönelik hazırlanmıştır. Araştırmada ele alınan ürünler, işlenmiş ve işlenmemiş tarım ürünlerinden oluşmaktadır. Anketlerde 5'li likert ölçeği şeklindeki soruların değerlendirilmesinde, verilen cevapların ortalaması kullanılmıştır (kesinlikle katılmıyorum: 1, katılmıyorum: 2, kararsızım: 3, katılıyorum: 4, kesinlikle katıliyorum: 5).

\section{Bulgular ve Tartışma}

Araştırma sonuçlarına göre, anket yapılan tüketicilerin \% 51.48'i kadın, \% 48.52'si erkeklerden oluşmaktadır. Tüketicilerin yaşı ortalama 36.55 yıl iken, eğitim süresi ortalama 12.37 yıldır. Evli olan tüketicilerin oranı (\% 58.31), bekâr olanların (\% 41.69) üzerindedir. Tüketiciler meslekleri yönünden incelendiğinde, memur (\% 22.78) ve işçilerin (\% 18.00) ağırlıkta olduğu görülmektedir. Hanehalk1 büyüklüğü ortalama 3.92 kişi olan ailelerin \% 11.72'sinde, çoğunluğunu yaşlıların oluşturduğu bakıma muhtaç kişiler bulunmaktadır. Tüketicilerin aylık geliri ortalama 3573.01 TL, toplam aile geliri ise ortalama 5577.26 TL olarak tespit edilmiştir (Tablo 1).

Tablo 1. Anket yapılan tüketici ve ailesine ait sosyoekonomik özellikler

\begin{tabular}{|c|c|c|}
\hline & & Ortalama \\
\hline \multirow{17}{*}{ 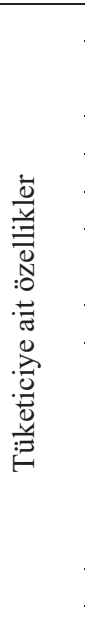 } & Cinsiyet (\%) & \\
\hline & Kadın & 51.48 \\
\hline & Erkek & 48.52 \\
\hline & Yaş (y1l) & 36.55 \\
\hline & Eğitim (y1l) & 12.37 \\
\hline & Medeni durum (\%) & \\
\hline & Evli & 58.31 \\
\hline & Bekâr & 41.69 \\
\hline & Meslek (\%) & \\
\hline & Çalışmıyor & 24.37 \\
\hline & Memur & 22.78 \\
\hline & İşçi & 18.00 \\
\hline & Esnaf & 15.26 \\
\hline & Emekli & 11.62 \\
\hline & Öğrenci & 7.97 \\
\hline & Gelir $\left(\mathrm{TL}_{\text {ay }}{ }^{-1}\right)$ & 3573.01 \\
\hline & Yurt dışında bulunma (\%) & 21.88 \\
\hline \multirow{5}{*}{ 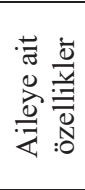 } & Nüfus (kişi) & 3.92 \\
\hline & Bakıma muhtaç kişi (\%) & 11.72 \\
\hline & 65 yaş ve üzerinde kişi (\%) & 18.23 \\
\hline & 6 yaş ve altında kişi (\%) & 20.57 \\
\hline & Toplam aile geliri $\left(\mathrm{TL}\right.$ ay $\left.{ }^{-1}\right)$ & 5577.26 \\
\hline
\end{tabular}

Tüketiciler bir ürünü satın alırken o ürünün kendine özgü özelliklerinin yanı sıra, yerli ya da ithal olmasını da göz önünde bulundurarak tercihlerini belirlemektedir. Anket yapılan tüketicilerin \% 55.99'u işlenmiş ya da işlenmemiş ithal tarım ürünlerini son bir yılda en az bir kez tükettiklerini ifade etmişlerdir. Tüketicilerin en fazla tercih ettikleri ithal tarım ürünleri; \% 57.37 ile baklagiller, \% 37.82 ile meyveler ve \% 19.87 ile et ve mamullerinden oluşmaktadır (Tablo 2). Erzincan ilinde yapılan bir araştırmada, ithal kırmızı et tercih eden tüketicilerin oranı \% 5.7 olarak tespit edilmiştir (Özyürek ve ark., 2019). Araştırma sonuçları, Türkiye'de ithal kırmızı ete karşı ilginin az olduğunu göstermektedir. Buna gerekçe olarak Topcu ve Uzundumlu (2012), ithal et kalitesinin düşüklüğü ve etin ciddi hastalık riski taşımasını göstermişlerdir. Tüketicilerin ithal bir ürüne karş1 gösterdikleri ilgi, yerli ürünlerin kalite ve fiyatlarına bağlı olarak zamanla değişebilecektir. İthalat yoluyla yurt içi piyasaya sunulan tarım ürünlerine yönelik olumsuz görüşlerin, ancak sürdürülebilir bir gıda güvenliği ve kalite standardının geliştirilmesiyle ortadan kaldırılması mümkündür.

Tablo 2. İthal tarım ürünleri tüketimi

\begin{tabular}{|c|c|c|c|}
\hline & & Say1 & $\%$ \\
\hline \multirow{3}{*}{$\begin{array}{l}\text { Tüketim } \\
\text { durumu }\end{array}$} & Tüketen & 215 & 55.99 \\
\hline & Tüketmeyen & 169 & 44.01 \\
\hline & Toplam & 384 & 100.00 \\
\hline \multirow{7}{*}{$\begin{array}{l}\text { Tüketilen } \\
\text { ürünler }\end{array}$} & $\begin{array}{l}\text { Baklagiller } \\
\text { (kuru fasulye, } \\
\text { mercimek, nohut, } \\
\text { pirinç) }\end{array}$ & 179 & 57.37 \\
\hline & $\begin{array}{l}\text { Meyveler } \\
\text { (avokado, ceviz, çilek, } \\
\text { mango, muz) }\end{array}$ & 118 & 37.82 \\
\hline & $\begin{array}{l}\text { Et ve mamulleri } \\
\text { (et, kiyma, salam, } \\
\text { sucuk) }\end{array}$ & 62 & 19.87 \\
\hline & $\begin{array}{l}\text { Sebzeler } \\
\text { (biber, domates, } \\
\text { patates, soğan) }\end{array}$ & 61 & 19.55 \\
\hline & $\begin{array}{l}\text { Tahıl ve ürünleri } \\
\text { (ayçiçeği, buğday, bulgur, } \\
\text { çeltik, makarna, misır) }\end{array}$ & 40 & 12.82 \\
\hline & Çay-Kahve & 18 & 5.77 \\
\hline & $\begin{array}{l}\text { Süt ve ürünleri } \\
\text { (süt, peynir) }\end{array}$ & 8 & 2.56 \\
\hline
\end{tabular}

Tüketicilerin yerli tarım ürünü tercihlerinde başlica gerekçe olarak, yerli üretimi (4.22) ve yerli gıda sanayini (4.22) korumak gösterilmiştir. İthal tarım ürünü tercih edenlerde ise en önemli gerekçe olarak; ürünün yüksek teknolojiyle üretilmesi (3.41), ürün fiyatının daha ucuz olması (3.21) ve ürünle ilgili denetimlerin fazla olması gösterilmiştir (3.07). Dolayısıyla tüketicilerin yerli 
tarım ürünü tercihinde daha çok milli duygu ve dini inanışlar etkili iken, ithal tarım ürünü tercihinde teknolojik özellikler ve fiyat öne çıkan faktörler olmaktadır (Tablo 3). Ankara ilinde yapılan bir araştırmada, ithal ürünlerin değerlendirilmesinde teknolojik özellikler (4.26) ve kalitenin (4.04) öncelikli unsurlar olduğu, yerli ürünlerin değerlendirilmesinde ise ülkeye duyulan güvenin (3.43) en başta yer aldığ1 tespit edilmiştir (Sertoğlu ve Çatlı, 2017). İthal tarım ürünlerine karşı tüketici tutum ve davranışlarını ele alan araştırma sonuçları, tüketicilerin yerli ürünlerden yana tutum sergilediklerini göstermektedir. Erzurum ilinde yapılan bir araştırmada, tüketicilerin 4.45 ile "Türk halk1, her zaman seçimini yerli et ve et ürünlerinden yana kullanmalıdır" ve 4.39 ile "Türkiye'de üretilen et ve et ürünleri her zaman benim için ön sırada yer alır" ifadeleri ilk iki sırada yer almaktadır (Kadanalı ve ark., 2014). Ankara ilinde yapılan diğer bir araştırmada ise "Türk yapımı ürünler satın alın, Türkiye'nin çalışmaya devam etmesini sağlayın" (3.8), "Türk yapımı ürünler her zaman önce gelir" (3.65) ve "Sadece Türkiye'de bulunamayan ürünler ithal edilmelidir" (3.54) görüşleri öne çıkmaktadır (Pekmezci, 2017). Türkiye'de 32 ili kapsayan bir araştırmada da, tüketicilerin Türkiye'de üretilen ürünlerin her zaman tercih edilmesi (3.3125) ve sadece Türkiye'de üretilmeyen ürünlerin ithal edilmesi (3.2909) konusundaki düşünceleri ilk iki sırada yer almaktadır (Özden ve Eser, 2019).

Tablo 3. Yerli ve ithal tarım ürünlerinin tercih edilme nedenleri

\begin{tabular}{|c|c|c|c|}
\hline & & Ortalama & Önem siras1 \\
\hline \multirow{8}{*}{ Yerli tarım ürünü } & Yerli üretimi korumak & 4.22 & 1 \\
\hline & Yerli g1da sanayini korumak & 4.22 & 1 \\
\hline & Yurt dışına para çıkışını istememek & 4.11 & 2 \\
\hline & Üretimin İslami usulde yapılması & 4.08 & 3 \\
\hline & Güvenilir olması & 4.07 & 4 \\
\hline & Kaliteli olması & 4.02 & 5 \\
\hline & Yerli marka alışkanlığı & 3.89 & 6 \\
\hline & Yabancı firmaların yurt içi pazara girişine engel olmak & 3.83 & 7 \\
\hline \multirow{8}{*}{ İthal tarım ürünü } & Yüksek teknolojiyle üretilmesi & 3.41 & 1 \\
\hline & Düşük fiyatlı olması & 3.21 & 2 \\
\hline & G1da denetimlerinin fazla olması & 3.07 & 3 \\
\hline & Güvenilir ve hijyenik olması & 2.95 & 4 \\
\hline & Kaliteli olması & 2.89 & 5 \\
\hline & Lezzetli olması & 2.74 & 6 \\
\hline & Besin değerinin yüksek olması & 2.58 & 7 \\
\hline & G1da katkı maddesinin az kullanılması & 2.49 & 8 \\
\hline
\end{tabular}

Tüketiciler ithal tarım ürünlerini satın alırken \% 83.59 ile en fazla gelişmiş ülkelere ait ürünlere güven duymaktadır. Tüketicilerin \% 76.30’u ithal tarım ürünleri açısından Müslüman ülkeleri daha güvenilir bulurken, geriye kalan \% 23.70' Müslüman olmayan gelişmiş ülkelerin daha güvenilir olduğunu düşünmektedir. Ayrıca tüketicilerin \% 29.95 ile en çok Asya Kıtası'nda yer alan ülkelere ve \% 24.22 ile Orta Doğu ülkelerine güven duydukları tespit edilmiştir (Tablo 4). Küreselleşmenin doğal bir sonucu olarak, farklı ülkelerden değişik markalı ürünlerin yaygın biçimde yer aldığı pazar ortamında, tüketicilerin söz konusu ürünleri ve markaları ait oldukları veya işlem gördükleri ülkelerle eşleştirmeleri doğal bir eğilim olarak kabul edilmektedir (Değermen ve ark., 2017). Tüketicilerin yabancı ülkeye ait bir ürüne ilişkin değerlendirmelerinde, ithalat yapılacak ülkenin tüketiciye verdiği imaj önemlidir. Ancak algılanan imajın her zaman olumlu olmaması, imajın önemli
Tablo 4. Tüketicilerin tarım ürünlerinin ithal edildiği ülkelere karşı güvenilirlik algısı

\begin{tabular}{lrr}
\hline & Say1 & \multicolumn{1}{c}{$\%$} \\
\hline Gelişmiş & 321 & 83.59 \\
Gelişmekte olan & 57 & 14.85 \\
Az gelişmiş & 6 & 1.56 \\
\hline Toplam & 384 & 100.00 \\
\hline Müslüman & 293 & 76.30 \\
Müslüman olmayan & 91 & 23.70 \\
\hline Toplam & 384 & 100.00 \\
\hline Asya & 115 & 29.95 \\
Orta Doğu & 93 & 24.22 \\
Amerika (Kuzey, Orta, Güney) & 78 & 20.31 \\
Afrika & 66 & 17.19 \\
Avrupa & 32 & 8.33 \\
\hline Toplam & 384 & 100.00 \\
\hline
\end{tabular}

ve iyi yönetilmesi gereken bir kavram olduğunu göstermektedir (Güleç, 2016). Tüketiciler daha önceden bilgi sahibi olmadıkları bir ürünle ilk defa karşılaştıklarında, o ürünün kalitesini anlamak için söz konusu ülkeye ait diğer ürünlerin kalitesine 
bakmaktadır (Vural, 2007). Yürekli ve Haşıloğlu (2018), eğer tüketici az gelişmiş bir ülkede yaşıyorsa, gelişmiş bir ülkeye ait ürünün cazip olduğunu ve bu durumun satın alma kararını olumlu etkilediğini, ancak aynı tüketicinin az gelişmiş bir ülkenin ürününe yönelik daha olumsuz bir algıya sahip olabildiğini belirtmişlerdir.

\section{Sonuç ve Öneriler}

Dünyada hiçbir ülke, başka bir ülkeye özellikle de tarım ürünleri açısından bağımlı olmak istemez. $\mathrm{Bu}$ nedenle ülkeler, tarım ürünleri arzını planlamayla belli ölçüde kontrol altına alıp, kendine yeterliliği sağlamayı hedeflerler ve tarım politikalarını oluştururken de bu stratejilerini her zaman ön planda tutarlar. Bu hedef doğrultusunda gelişmiş ülkeler başta olmak üzere bütün ülkeler, tarım ürünlerinde verim artışı sağlayan tekniklerin geliştirilmesi konusunda son yıllarda yoğun gayret göstermektedir. Ancak yurt içi üretimin yeterli olmadığ1 yıllarda sürdürülebilir bir gıda arzının sağlanması için, bazı tarım ürünlerinin ithal edilmesi kaçınılmaz hale gelmektedir. $\mathrm{Bu}$ nedenle ithal tarım ürünleri konusunda tüketicilerin tutum ve davranışlarını esas alan araştırmaların yapılması ve bu ürünlerin pazarlanmasına yönelik modellerin oluşturulması, uluslararası pazarda faaliyet gösteren tüm firmalar açısından büyük önem taşımaktadır. Bu sayede yerli firmalar müşterilerini kaybetmemek için gerekli önlemleri almış olacak, yabancı firmalar ise daha fazla müşteri kazanmak için tüketici tercihlerine yönelik stratejiler geliştirebileceklerdir.

Türkiye'de geçmişte olduğu gibi günümüzde de birçok işlenmiş ve işlenmemiş tarım ürününde ithalat yapılmaktadır. Tarım ürünleri ithalatı sınırlı miktarda yapıldığı için, hiçbir zaman yerli üretimi etkileyecek boyuta ulaşmamıştır. Ancak son yıllarda özellikle canlı hayvan başta olmak üzere, tarım ürünleri ithalatında önemli bir artış söz konusudur. Türkiye, tarımsal üretim ve gıda sanayinde önemli potansiyele sahip bir ülkedir. Bu sektörlerde, çok fazla işletme faaliyet göstermekte ve önemli ölçüde nüfus istihdam edilmektedir. Bu nedenle yerli ürün arzının nüfus artışına bağlı olarak planlanması ve yerli ürün talebinde sürekliliğin sağlanması son derece önemlidir. Samsun ili kentsel alanda yaşayan tüketicilerin ithal tarım ürünlerine yönelik tutum ve davranışlarının analiz edildiği bu araştırma, tüketicilerin büyük bir kısmının ithal tarım ürünlerinin tüketimi konusunda olumlu tutum sergilediklerini göstermektedir. Araştırma alanında baklagiller ve meyvelerin en çok tercih edilen ithal tarım ürünleri olması, tüketicilerin temel besin kaynağını oluşturan bu ürünlerin ithal edilmesine karşı olumlu tutum sergilediklerini göstermektedir.
Araştırma sonuçlarına göre tüketiciler, ithal tarım ürünlerinin yüksek teknolojiyle üretildiği ve yerli ürünlere göre fiyatlarının daha düşük olduğu düşüncesiyle tercih ettiklerini belirtmişlerdir. Yerli tarım ürünlerinin tercih edilmesinde ise, yerli üretimde devamlılığın sağlanmasını amaçlayan milli duygular öne çıkmaktadır. Tüketicilerin yerli ürünleri tercih etme sıralamasında, güvenilirlik ve kalite gibi nedenler daha gerilerde kalmaktadır. Son yıllarda gida sanayinde faaliyet gösteren firmalar arasında yaşanan yoğun rekabet ortamında, firmaların kârlarını artırarak piyasadaki varlıklarını devam ettirebilmeleri için, tüketici odaklı üretim anlayışını ve buna yönelik pazarlama stratejilerinin benimsenmesi zorunlu hale gelmiştir. $\mathrm{Bu}$ nedenle tüketicilerin güvenilir ve kaliteli yerli ürünlere olan ihtiyaçlarının sağlanması konusu, yerli firmaların öncelikli hedefleri arasında yer almalıdır.

Türkiye'de tüketicinin ithal bir ürüne karşı güven algısında, ithalatçı ülkelerle olan ilişkilerin de önemli oranda etkili olduğu bir gerçektir. Dolayısıyla, uluslararası ticareti kisıtlayan unsurların giderilmesinde, ekonomik ilişkilerle birlikte sosyal ve siyasi ilişkilerin güçlendirilmesi de büyük önem arz etmektedir. Uluslararası pazarda yaşanan yoğun rekabet ortamında firmalar, tüketici istek ve ihtiyaçlarına göre hareket etmek ve buna yönelik stratejiler geliştirmek zorundadır. Tüketici tercihleri pek çok faktörden etkilendiği için esas hedef, tüketici kitlesinin doğru analiz edilmesi ve uygun pazarlama yönteminin belirlenmesi olmalıdır. Araştırmada, tüketicilerin Müslüman ülkelere karşı daha fazla güven duyması, tüketicilerin İslami usullere uygun ürün taleplerinin yoğun olduğunu göstermektedir. Dolayısıyla tarım ürünleri dış ticaretinde yer alan firmaların, dini konulara yönelik tüketici hassasiyetini gözetmeleri ve bu doğrultuda standartlar geliştirmeleri büyük önem taşımaktadır.

\section{Kaynaklar}

Barlett, J.E., Kotrlik, J.W., Higgins, C.C., 2001. Organizational research: Determining appropriate sample size in survey research. Information Technology, Learning, and Performance Journal, 19(1): 43-50.

Değermen, A., Doğan, E., Noyan, A., 2017. Tüketicilerin yabanc1 cep telefonu markalarını yeniden satın alma niyetleri üzerinde etnosentrizm ve kurumsal imajın etkisi. Kocaeli Üniversitesi Sosyal Bilimler Dergisi, 34: 101-124.

Eryılmaz, G.A., Kılıç, O., Başer, U., 2018. Gıda güvenliği konusunda tüketici davranışlarının belirlenmesi: Samsun ili kentsel alan örneği. Çanakkale Onsekiz Mart Üniversitesi Fen Bilimleri Enstitüsü Dergisi, 4(2): 237-245. 
Güleç, Ş.N., 2016. Özel hastane tercihinde kurumsal imajın rolü üzerine teorik ve uygulamalı bir çalışma. Yüksek lisans tezi, Selçuk Üniversitesi Sosyal Bilimler Enstitüsü, Konya.

Kadanalı, E., Demir, N., Dağdemir, V., Turan, E.A., 2014. Et ve et ürünleri satın alma kararlarında tüketici etnosentrizminin belirlenmesi; Erzurum ili örneği. XI. Ulusal Tarım Ekonomisi Kongresi, Bildiriler Kitab1, 3-5 Eylül, Samsun, s. 1333-1339.

Öndoğan, E.N., 2002. Türkiye'de işlenmiş ithal gıda ürünleri pazarlaması. Ege Akademik Baklş Dergisi, 2(2): 93-104.

Özden, A.T., 2017. Etnosentrik eğilimin tüketicilerin satın alma davranışına etkisi: Doğu Anadolu ve Karadeniz bölgeleri üzerine karşılaştırmalı analiz. Doktora tezi, Başkent Üniversitesi Sosyal Bilimler Enstitüsü, Ankara.

Özden, A.T., Eser, Z., 2019. The effect of ethnocentric tendency on buying behaviour in terms of consumers' self-perception and ethnicity: Sample of Turkey. Journal of Research in Business, 4(2): 124146.

Özyürek, S., Çebi, K., Türkyılmaz, D., Esenbuğa, N., Dağdelen, Ü., Yaprak, M., 2019. Erzincan ilinde kırmızı et tüketim alışkanlıkları ve tüketicilerin ithal kırmızı ete bakış açılarının değerlendirilmesi. Erzincan Üniversitesi Fen Bilimleri Enstitüsü Dergisi, 12(1): 263-273.

Pekmezci, P., 2017. Ailelerin etnosentrik gıda ürünleri tüketim davranışları: Kuşaklararası bir inceleme. Yüksek lisans tezi, Hacettepe Üniversitesi Sosyal Bilimler Enstitüsü, Ankara.

Sertoğlu, A.E., Çatll, Ö., 2017. Genç tüketicilerin yabancı ve Türk ürünlerine ilişkin tutum ve tüketici etnosentrizm düzeylerini belirlemeye yönelik bir araştırma. Gazi Üniversitesi İktisadi ve İdari Bilimler Fakültesi Dergisi, Özel Sayıs1: 1-23.

Şahin, E , Sancı, T ., 2017. Satın alma kararlarında tüketici etnosentrizmi ve menşe ülke etkisi: Selçuk Üniversitesi İktisadi ve İdari Bilimler Fakültesi'nde bir uygulama. Sosyal Ekonomik Araştırmalar Dergisi, 17: 145-169.

Tekin, M., Şahin, E., Göbenez, Y., 2014. Postmodern pazarlama yaklaşımıyla modern pazarlama yöntemleri: Güncel şirket uygulamaları. Selçuk Üniversitesi Sosyal Bilimler Enstitüsü Dergisi, Dr. Mehmet Yıldız Özel Sayısı: 225-232.

Topcu, Y., Uzundumlu, A.S., 2012. Tüketicilerin kırmızı et tüketimi ile ilgili tutum ve davranışlarını etkileyen faktörlerin analizi: Erzurum ili örneği. X. Ulusal Tarım Ekonomisi Kongresi, Bildiriler Kitab1, 5-7 Eylül, Konya, s. 926-935.

Vural, R.K., 2007. Tüketici davranışını etkileyen bir faktör olarak kaynak ülke etkisinin değerlendirilmesi. Yüksek lisans tezi, Ankara Üniversitesi Sosyal Bilimler Enstitüsü, Ankara.

Yalçın, S., 2003. Pazarlama, Dış Pazarların Belirlenmesi. Başbakanlık Dış Ticaret Müsteşarlığ1 İhracat Genel Müdürlüğü, İzmir Ticaret Odası Dış Ticaret Eğitim Programı, İzmir.

Yücel A., Şimşek A.İ., 2018. Tüketici davranışlarını analiz etmede nöropazarlama yöntem ve araçlarının kullanımı. İп̈̈ӥ̈ Üniversitesi Uluslararası Sosyal Bilimler Dergisi, 7(1): 118-142.

Yürekli, E., Haşıloğlu, S.B., 2018. Etnosentrik düzeyine göre farklı ülke menşeli ürünlerin algısı: Kırgız öğrenciler örneği. Pamukkale Journal of Eurasian Socioeconomic Studies, 5(2): 31-40. 